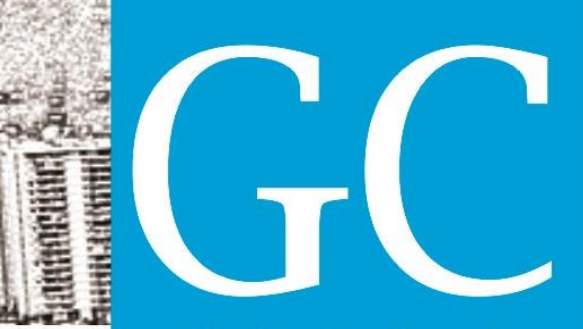

Revista Nacional de Gerenciamento de Cidades

\title{
PRODUÇÃO DO ESPAÇO URBANO: OS CONJUNTOS HABITACIONAIS EM ITUIUTABA (MG)
}

\author{
Luciana Domingues Chaves ${ }^{1}$
}

\author{
José Vieira Neto ${ }^{2}$
}

\begin{abstract}
RESUMO
Para Carlos (1994), a produção do espaço urbano assume, desde algumas décadas, função importante e ativa na dinâmica econômica do modo capitalista de produção, seja enquanto condição, produto e meio deste processo. Nesse viés, pode-se considerar o espaço urbano enquanto resultado das ações dos agentes que atuam e consomem este, segundo anseios e necessidades próprias, o que, por consequência, acarretam práticas que o (re)produzem de modo desigual. Nessa lógica desigual, a demanda por habitação social emerge como fator crucial no cenário nacional durante o período de industrialização no Brasil, com necessidade de intervenção do Estado, uma vez, que o mercado privado isoladamente se mostrou insuficiente para resolver o déficit habitacional principalmente para as famílias de baixa renda. Nessa conjuntura objetiva-se neste artigo analisar a importância dos conjuntos habitacionais na produção do espaço urbano da cidade de Ituiutaba (MG). Para tanto, foram realizados os seguintes procedimentos metodológicos: levantamento bibliográfico, revisão de literatura e análises empírica. Por fim, pode-se concluir que as mudanças ocorridas em Ituiutaba por intermédio do lançamento de novos produtos imobiliários, neste caso, os conjuntos habitacionais propiciaram significativas transformações na paisagem urbana, bem como redesenharam os limites urbanos.
\end{abstract}

PALAVRAS-CHAVE: Produção do Espaço Urbano. Conjuntos habitacionais. Ituiutaba (MG).

\section{PRODUCTION IN URBAN SPACE: THE HOUSING COMPLEXES IN ITUIUTABA (MG)}

\footnotetext{
${ }^{1}$ Geógrafa. Mestranda do Programa de Pós-graduação da Universidade Federal de Goiás - Regional Catalão, Bolsista CAPES, lucianachavesitba@gmail.com.

2 Geógrafo. Professor Dr. do Programa de Pós-graduação da Universidade Federal de Goiás Regional Catalão, jovineto@hotmail.com.
} 
Revista Nacional de

Gerenciamento de Cidades

agentes (proprietários dos meios de produção; proprietários fundiários; promotores imobiliários; Estado e; grupos sociais excluídos), leva a um quadro de complexidade, "isto porque estes agentes operam no processo de construção da cidade segundo anseios e necessidades próprias de cada grupo, o que, por consequência, produz de modo descontínuo e diferenciado o espaço urbano" (TAVARES, 2009, p. 36).

Considerando tais pressupostos, elucida-se que o processo de produção capitalista atinge fortemente as cidades, em especial os grandes centros urbanos, induzindo a diferenciação das formas de uso e ocupação das áreas. Tais desigualdades se manifestam intensamente nas táticas de sobrevivências da população menos favorecida economicamente que, por sua vez, refletem diretamente nos espaços habitados e nas formas de ocupação do solo. Nesse viés, os conjuntos de habitação de interesse social refletem um espaço urbano de desigualdades e contradições sociais.

Nessa conjuntura, objetiva-se neste artigo analisar a importância dos conjuntos habitacionais na produção do espaço urbano da cidade de Ituiutaba (MG). Para tanto, foram realizados os seguintes procedimentos metodológicos: levantamento bibliográfico e revisão de literatura, de temas como: produção do espaço urbano e seus agentes modeladores e habitação. Simultaneamente a essa etapa foi realizada a pesquisa empírica na cidade in lócus agregando nas análises acerca das mudanças estabelecidas no espaço urbano pelos conjuntos habitacionais.

A cidade de Ituiutaba, recorte espacial deste estudo, é sede de município localizado na Mesorregião Geográfica do Triângulo Mineiro e Alto Paranaíba, mais especificamente na Microrregião ${ }^{3}$ de Ituiutaba (figura 1).

\footnotetext{
${ }^{3}$ O Instituto Brasileiro de Geografia e Estatística (IBGE) define Microrregião como sendo: um conjunto de municípios, contíguos e contidos na mesma Unidade da Federação, definidos com base em características do quadro natural, da organização da produção e de sua integração.
} 
Figura 1. Microrregião de Ituiutaba (MG): localização do município e do perímetro urbano de Ituiutaba, 2014

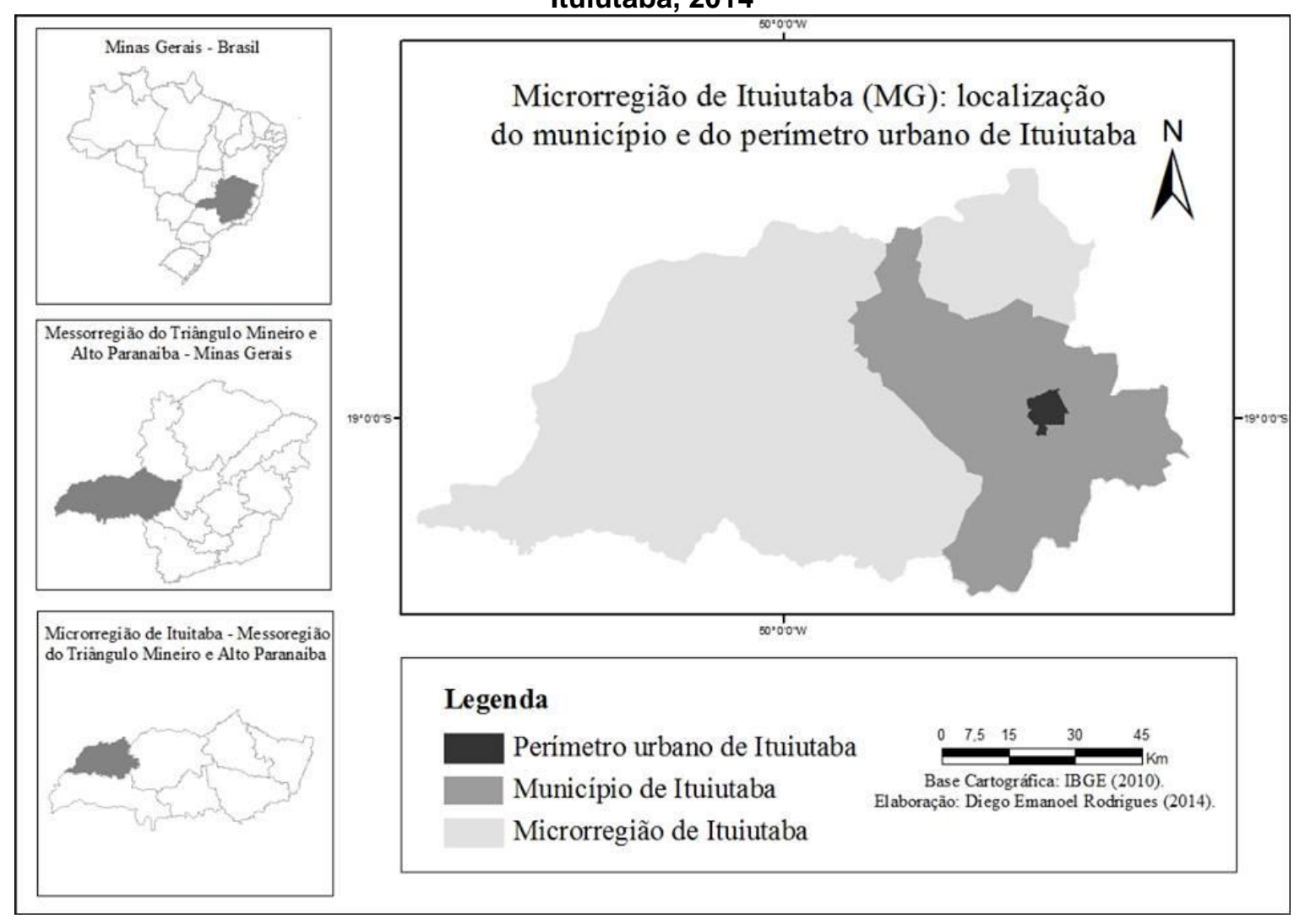

Em linhas gerais, do ponto de vista econômico, nas décadas de 1960/70 a rizicultura atinge seu ápice e se consolida no cenário econômico do município de Ituiutaba. Assim, com base no capital originado pelo arroz,

[...] a cidade começou a melhorar equipar-se com serviços de água, energia elétrica, comércio e serviços diversificados, expansão de loteamentos urbanos e novas atividades, que iria beneficiar a população, que crescia vertiginosamente nesse período [...] As mudanças no espaço urbano ocorreram paralelamente às do espaço rural: "levas" de trabalhadores nordestinos chegaram ao município de Ituiutaba e tornaram-se agentes transformadores do campo, responsabilizados pelas roças de arroz, milho e feijão [...] O Capital investido no campo teve retorno na cidade de modo gradual: cresceu o numero de habitantes, residências e casas de comércios, serviços e indústrias ligadas à atividade agrícola (OLIVEIRA, 2003, p.16-17; 64). 
Neste panorama de transformações há uma inversão dos dados em relação aos aspectos populacionais evidenciando-se maior número de pessoas vivendo na área urbana do município conforme demonstrado na tabela 1, fato que culminou com os projetos governamentais desenvolvidos para a área do Cerrado, desenvolvendo o campo (grandes propriedades) fazendo com que população deste viesse para a cidade (êxodo rural) devido à mecanização do meio rural. Neste contexto, como nos aponta Oliveira (2003), houve a expansão de novos loteamentos urbanos, bem como emergiu novas atividades nos diferentes setores da economia para contemplar a população que crescia notoriamente neste período em Ituiutaba.

Tabela 1. Ituiutaba (MG): dinâmica da população total, e percentual da população urbana e rural (1950-2010)

\begin{tabular}{lccccc}
\hline Ano & Total & $\begin{array}{c}\text { População } \\
\text { Urbana }\end{array}$ & $\begin{array}{c}\text { População } \\
\text { Rural }\end{array}$ & $\begin{array}{c}\text { População } \\
\text { Urbana (\%) }\end{array}$ & $\begin{array}{c}\text { População } \\
\text { Rural (\%) }\end{array}$ \\
\hline 1950 & 53.240 & 10.113 & 43.127 & 19,00 & 81,00 \\
1960 & 68.218 & 30.698 & 37.520 & 45,00 & 55,00 \\
1970 & 64.528 & 46.784 & 17.744 & 72,50 & 27,50 \\
1980 & 74.247 & 65.153 & 9.094 & 87,75 & 12,25 \\
1991 & 84.577 & 78.205 & 6.372 & 92,46 & 7,54 \\
2000 & 89.091 & 83.853 & 5.238 & 94,12 & 5,88 \\
2010 & 97.171 & 93.125 & 4.046 & 96,00 & 4,00 \\
\hline
\end{tabular}

Fonte: Censos Demográficos - Instituto Brasileiro de Geografia e Estatística (IBGE): 1950, 1960, 1970,1980, 1991, 2000 e 2010. Org.: CHAVES, Luciana Domingues,2013.

$\mathrm{Na}$ primeira década de 2010, Ituiutaba passou por um processo marcado pela atuação do capital e do poder público no espaço urbano, os quais propiciaram significativas transformações na paisagem urbana, sobretudo através de investimentos e lançamento de novos produtos imobiliários bastantes elucidativos na reestruturação da cidade. A título de exemplo, citam-se os investimentos subsidiados pelos governos federal e estadual, no setor da moradia popular, os quais redesenharam os limites urbanos.

\section{DESENVOLVIMENTO}


Revista Nacional de

Gerenciamento de Cidades

\subsection{Produção do espaço urbano e habitação: apontamentos teóricos e conceituas}

O espaço urbano é um espaço socialmente construído, humano, mas, sobretudo, o espaço da realização do capital, uma vez que "no modo de produção atual e na 'sociedade em ato' tal como ela é, o espaço tem assumido, embora de maneira distinta, uma espécie de realidade própria, ao mesmo título e no mesmo processo global que a mercadoria, o dinheiro, o capital" (LEFEBVRE, 2001, p. 36).

É neste contexto do modo de produção capitalista que Corrêa (2005, p. 11) caracteriza o espaço urbano como simultaneamente "fragmentado, articulado, condicionante social, cheio de símbolos e campo de lutas" e, portanto, trata-se de "um produto social, resultado de ações acumuladas através do tempo, e engrenadas por agentes que produzem e consomem espaço". Para, Souza (1994, p. 186) designar as ações destes agentes produtores do espaço urbano, não é tarefa fácil, pois, em "várias situações, eles se confundem ao realizar mais de uma função específica, fazendo o papel de dois ou mais agentes em um mesmo processo".

Então finalmente, pode-se considerar o espaço urbano enquanto resultado das atuações dos diversos agentes que atuam e consomem este, segundo anseios e necessidades próprias, o que, por consequência, acarretam práticas que o (re)produzem de modo desigual.

Ao mesmo tempo em que o espaço urbano se (re)produz de modo desigual , Spósito (1994, p.13) pontua que as cidades também apresentam características peculiares que as diferenciam uma das outras, cada uma "tem a sua história; contém sua própria identidade, marcada por diferenças e semelhanças [...] existem as pessoas que lá morram". A partir dessa concepção, o autor destaca um "problema" similar ocorrente nos países do chamado do Terceiro Mundo, a falta de habitações para muitos de seus habitantes. Todavia, "a habitação aparece como problema, para aquelas pessoas que não ganham muito dinheiro, ou porque são analfabetos, ou porque não possuem empregos com altos salários, enfim, são trabalhadores, que muita das vezes, não tem sequer um emprego!" (p.40). É nesse cenário que o mesmo autor acrescenta que, é necessário pensar uma solução para as pessoas 


\section{Revista Nacional de}

terem um lugar para morar, por conseguinte afirma que "esse "problema" é gerido pelo governo através do estímulo à autoconstrução e pelo financiamento da construção de casas e edifícios para abrigarem os despossuídos de moradias" (p.39).

No âmbito nacional, Campos (2011, p. 67) argumenta que "é cada vez mais difícil, no Brasil, distinguir a produção privada e a produção pública da habitação, especialmente quando esta se direciona a população de baixa renda, pois se encontram-se fortemente imbricadas na dinâmicas de produção do espaço das cidades brasileiras".

Maricato (1997, p.31) faz referência ao problema habitacional no âmbito nacional, chamando atenção para o fato de que como questão social a crise habitacional emergiu no final do século XIX devido à ampliação do crescimento urbano advindo com o fim da mão de obra escrava que "resultou em mudanças acentuadas na condição da moradia", ou seja, aumentou-se a demanda por habitação. Campos (2011, p.67) corroborando-se a Bonduki (2004) soma a essa discussão dizendo que:

[...] foi durante a ditadura de Vargas, entre os anos de 1930 a 1945, que o problema da moradia do operário brasileiro emergiu como fator crucial no cenário nacional, o que colocou em cena o tema da habitação social como uma força jamais vista. Sem duvida, a concentração urbana, a consciência do déficit habitacional, o crescimento das favelas e a pressão social, contribuíram para o novo direcionamento dado pelo Estado à questão habitacional, que passou a ser considerada como uma questão de política pública.

Nesse sentido, quando a questão habitacional passa a ser ponderada como um assunto de extrema proeminência, na qual o mercado privado não tinha mais condição de resolver à problemática, ficando a cargo do Estado a responsabilidade, instituíram-se políticas habitacionais com o intuito de solucionar a deficiência habitacional no país. Em síntese, busca-se apresentar de modo geral os projetos/programas instituídos colocados em práticas a partir desse momento.

Logo, explanamos que a primeira intervenção direta do governo federal na produção habitacional social da década de 1940 até 1960, ficou a cargo dos 
Revista Nacional de

Gerenciamento de Cidades

Institutos de Aposentadorias e Pensões (IAPs), os quais iriam financiar a construção de 140 mil moradias, tendo sua maior parte destinada ao aluguel, contudo o sistema de financiamento dos IAPs entrou em declínio, acarretado pela crise da previdência e desequilíbrios de fundos. Em 1946 criou-se a Fundação da Casa Popular (FCP), contemplando especificamente a provisão de moradias para as classes de baixa renda, em 18 anos de existência financiou a construção de apenas 16.964 moradias, sem contar com recursos próprios e com estrutura precária tornou-se insatisfatório. No ano de 1964, constitui-se o Sistema Financeiro de Habitação (SFH), cujo principal agente da política habitacional brasileira era o Banco Nacional de Habitação (BNH). Nenhum destes projetos/programas conseguiu propor soluções que resolvessem de forma definitiva o problema habitacional no Brasil (CAMPOS, 2011, p. 67-68; MARICATO, 1997, p. 36).

Campos (2011, p. 69), acrescenta que "[...] o BNH não apenas não solucionou o problema da habitação popular [...] como também contribuiu fortemente para a deterioração física e social das cidades brasileiras e para a associação entre legalidade e privilégio, medida por um mercado imobiliário elitizado e excludente".

Neste contexto, Pinheiro (2011), afirma que o Estado interfere diretamente no mercado imobiliário, proporcionando uma dinâmica do consumo do solo que muitas vezes beneficia os interesses de grupos sociais economicamente mais fortes. Acrescentando-se a isso, Villaça (2001, p. 335) destaca que "as camadas de mais alta renda controlam a produção do espaço urbano por meio de três mecanismos: um de natureza econômica - o mercado, no caso, fundamentalmente o mercado imobiliário; outro de natureza política: o controle do Estado, e, finalmente, através da ideologia".

Campos (2011, p.69) ressalta que na tentativa de por fim a estagnação em relação à política habitacional que foi posta em curso em 1996, pelo governo Fernando Henrique Cardoso, a Política Nacional de Habitação (PNH), o qual admitiu a necessidade da participação privada conjuntamente com o setor público na produção habitacional, devido às lacunas na área do desenvolvimento urbano e habitacional, bem como reconheceu de que 
[...] não se pode pensar em habitação isoladamente do contexto da cidade, ou seja, é fundamental garantir à população também o acesso a infraestruturas urbanas; o reconhecimento da função social da terra e da necessidade de regulação com o intuito de evitar a sua utilização especulativa, sobretudo em detrimento do acesso a terra pela população de baixa renda. (CAMPOS, 2011.p 69).

Analisando o processo recente brasileiro, o programa Minha Casa Minha Vida (MCMV), é considerado uma das principais ações do governo de Luis Inácio Lula da Silva (2003-2010), para solucionar o problema habitacional do país. O programa foi lançado pela Lei № 11.977 de julho de 2009, com o objetivo de "criar mecanismos de incentivo à produção e aquisição de novas unidades habitacionais ou requalificação de imóveis urbanos e produção ou reforma de habitações rurais, para famílias com renda mensal de até $R \$ 4.650,00$ (quatro mil, seiscentos e cinquenta reais)" (LEI № 11.977. 2009). A meta do programa visou construir um milhão de moradias com um investimento previsto de 60 bilhões de reais. E ainda, o número de unidades habitacionais por empreendimento é estabelecido em função da área e do projeto, limitado sempre em 500 unidades. As unidades habitacionais apresentam tipologia de casas térreas $\left(36 \mathrm{~m}^{2}\right)$ ou apartamentos $\left(39 \mathrm{~m}^{2}\right)$.

Nesse movimento de satisfatória realização da redução do déficit habitacional

Em 16 de julho de 2011, a Presidente da República Dilma Rousseff anunciou o lançamento do Minha Casa Minha Vida 2, ampliando a meta do programa para a construção de dois milhões de novas unidades habitacionais entre os anos de 2011 e 2014, com o investimento de 125,7 bilhões de reais. Para a população de faixa de renda até três salários mínimos, o MCMV 2 elevou a meta de atendimento de $40 \%$ para $60 \%$. Para as famílias que têm renda entre seis salários mínimos, a meta corresponde a $30 \%$ e para a faixa de renda entre seis e 10 salários mínimos a meta corresponde a 10\% das unidades a serem construídas (CAMPOS, 2011, p.75).

Nesse processo, observa-se como a atuação dos agentes produtores do espaço urbano modifica este conforme as especificidades de cada cidade, neste caso, a construção das unidades habitacional para a população menos favorecida economicamente, manifesta a (re)produção desigual do espaço urbanos as quais são refletidas nas cidades. 
Além dos conjuntos supracitados, outros foram edificados por intermédio do Programa Lares Habitação Populares de Minas Gerais e com recursos federais do Orçamento Geral da União (OGU) do Ministério das Cidades. No âmbito destes dois programas foram construídas 316 moradias, distribuídas nos Residencial Carlos Dias Leite e Residencial Tupã. Em linhas gerais, o Programa Lares Habitação Popular foi criado através do Decreto 44168/2005 de 06/12/2005, no âmbito do Fundo Estadual de Habitação (FEH), sob-responsabilidade da Companhia de Habitação do Estado de Minas Gerais (COHAB/MG). No que cerne, os recursos federais provenientes do Orçamento Geral da União (OGU) do Ministério das Cidades, Nascimento (2011, p.83-84) explica que o mesmo está "[...] inserido na política habitacional do Programa Habitação de Interesse Social do Governo Federal". Ambos os programas, tem como intuito a redução do déficit habitacional, contemplando famílias de baixa renda com rendimento mensal de até três salários mínimos.

Em relação ao padrão arquitetônico das unidades habitacionais dos três programas implementados em Ituiutaba possuem a seguinte configuração básica: dois quartos, sala, cozinha, banheiro e área de serviço. Nota-se que o projeto padrão prioriza o baixo custo e, dessa maneira, os materiais utilizados na construção ficam reduzidos no que diz respeito à quantidade e qualidade. Diante dessa realidade, nos deparemos com a repetição de infindáveis casinhas idênticas (figura 3). 
Fica, pois, evidente que os conjuntos habitacionais criaram novos espaços na cidade, bem como incrementaram a especulação imobiliária, tomemos, como exemplo, o bairro Santa Edwiges (figura 4). Sobre o bairro, explana-se em linha gerais que o mesmo é um loteamento aberto implantando na década de 1990. Em relação à infraestrutura básica e serviços é possível identificar a existência de infraestrutura mínima nos seguintes aspectos: sistema de esgoto sanitário, abastecimento de água potável, energia elétrica pública e domiciliar e coleta de lixo. Apenas uma rua de circulação possui pavimentação. E ainda não há posto de saúde - PSF e nem escola, o que faz com que os moradores se deslocam para outros bairros para buscar tais serviços. Outro fator importante que chama atenção são as chamadas "chácaras" existentes no bairro, estabelecendo uma combinação entre características do rural e do urbano ${ }^{4}$.

Nesta conjuntura, baseando-se em Santos (1996), o presente bairro se insere dentro da lógica dos espaços de lentidão, uma vez, que o "[...] o novo não chega a todos os lugares no mesmo momento histórico" (SAQUET, 2000, p. 111), resultando no desenvolvimento desigual entre os lugares. No entanto, a dinâmica de edificações dos conjuntos habitacionais Canaã I, Canaã II, Buritis e do condomínio semiaberto Portal dos Ipês proporcionaram a valorização do preço do metro quadrado neste bairro, tomemos, como exemplo, os anos de 2000 e 2014, nos quais o preço médio do metro quadrado era respectivamente de $R \$ 1,66$ (um real e sessenta e seis centavos) e $R \$ 45,36$ (quarenta e cinco reais e trinta e seis centavos). Nota-se que nesta dinâmica de lançamento de novos empreendimentos está imbricada uma gama de processos correlatos à produção do espaço urbano que, direta ou indiretamente, influencia para a evolução do preço nos mercados de terra urbana não edificada.

\footnotetext{
${ }^{4}$ Informações obtidas junto ao estudo "Proposições de melhoria da qualidade urbana por meio de diagnostico encontrado no bairro Santa Edwiges (Ituiutaba - MG)", realizado pelos discentes Andressa Soares Guimarães, Bruno de Freitas, Leilaine Ferreira de Fátima e Luciana Domingues Chaves, na disciplina Planejamento Urbano do Curso de Geografia da FACIP/UFU - $2^{\circ} \circ \mathrm{sem} / 2012$.
} 


\section{Revista Nacional de \\ Gerenciamento de Cidades}

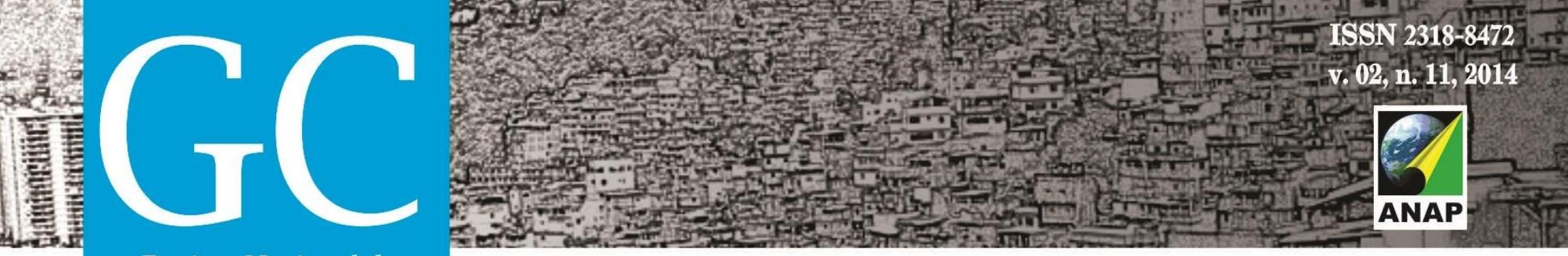

Figura 4. Ituiutaba (MG): localização do bairro Santa Edwiges, 2013
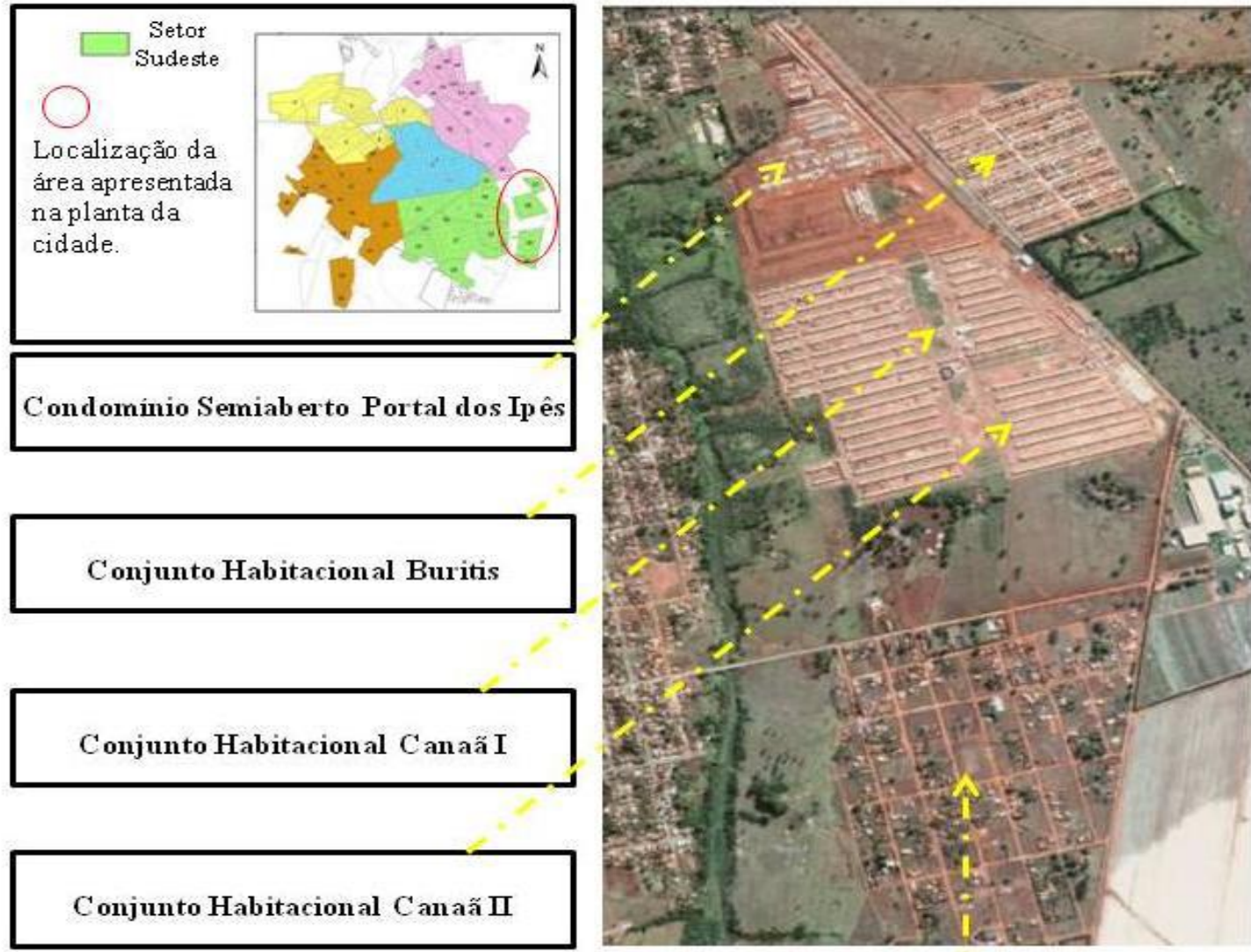

Conjunto Habitacional Canaã II
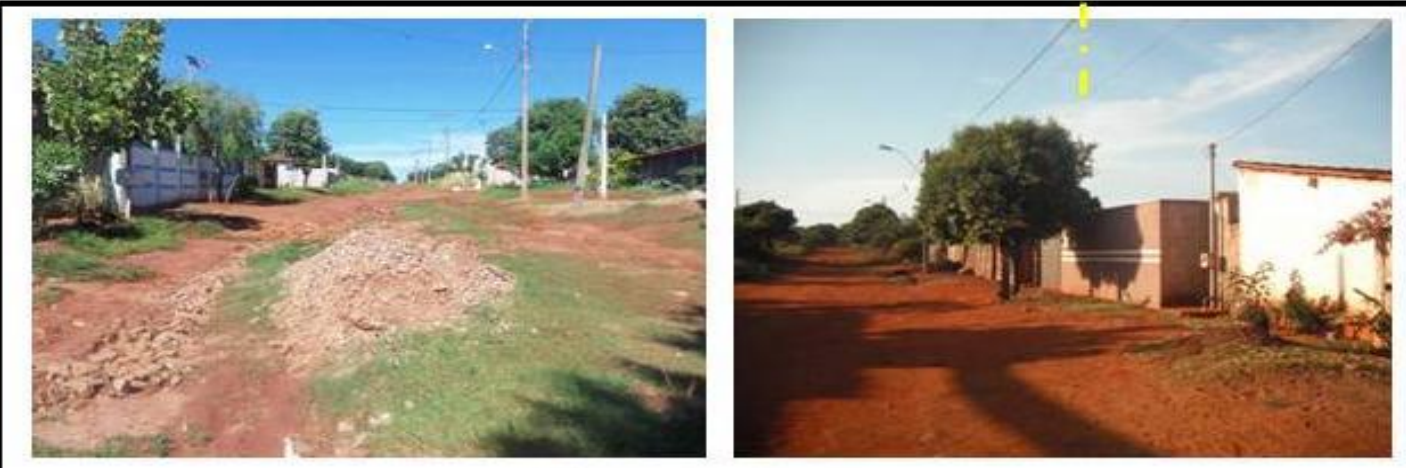

Bairro Santa E dwiges

Fonte: CHAVES, Luciana Domingues, 2013 (fotos); Google Earth, 2013 (imagem de satélite).

Diante do exposto, pode-se perceber por intermédio das análises e discussões in lócus que a implementação dos conjuntos de habitação de interesse social ao mesmo tempo em que visa à redução do déficit habitacional no âmbito nacional, reflete um espaço urbano de desigualdades e contradições sociais. 


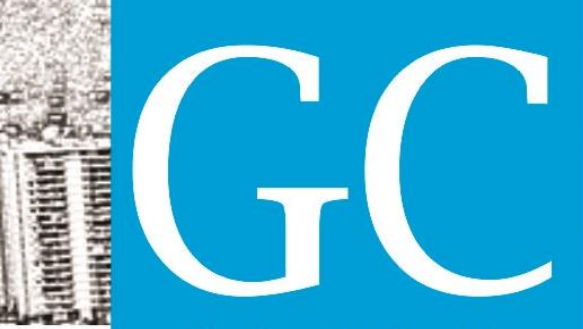

Revista Nacional de

Gerenciamento de Cidades

\section{CONCLUSÃO}

Por fim, mas não menos importante podemos concluir que as mudanças em Ituiutaba por intermédio da implementação dos conjuntos de interesse social, bem como, de outros produtos imobiliários propiciaram significativas transformações na paisagem urbana da cidade, assim como redesenharam seus limites urbanos. E ainda, intensificaram a valorização de determinadas área no tocante a potencial valorização imobiliária.

\section{REFERÊNCIAS}

BRASIL. Lei no 11.977, de 7 de julho de 2009. Disponível em:<http://www.planalto.gov.br/ccivil_03/_at to2007-2010/2009/lei/l11977.htm> Acesso em 15 de jun. de 2013.

CARLOS, Ana Fani Alessandri. A (re)produção do espaço urbano. 1 ed. São Paulo: EDUSP, 1994.

CORRÊA, Roberto Lobato. O espaço urbano. 4 ed. São Paulo: Ática, 2005.

CORRÊA, Roberto Lobato. Sobre agentes sociais, escala e produção do espaço: um texto para discussão. In: CARLOS, Ana Fani Alessandri; SOUZA, Marcelo Lopes; SPOSITO, Maria Encarnação Beltrão (orgs.). A produção do espaço urbano: agentes e processos, escalas e desafios. 1 ed., 2 reimp. São Paulo: Contexto, 2013. p. 41-51.

CAMPOS, Paola Rogedo. O preço da terra urbana e moradia de baixo custo. In: MENDONÇA, Jupira Gomes de; COSTA, Heloisa Soares de Moura (orgs.). Estado e Capital Imobiliário: convergências atuais na produção do espaço urbano brasileiro. Belo Horizonte: C/Arte, 2011. p. 63-79.

FERREIRA, Leilaine de Fátima. Programa Minha Casa Minha Vida em Ituiutaba (MG): uma análise dos conjuntos habitacionais Buritis, Canaã I e Canaã II. 2013. 90f. Trabalho de conclusão de curso (Graduação em Geografia) - Faculdade de Ciências Integradas do Pontal, Universidade Federal de Uberlândia, Ituiutaba, 2013.

IBGE - Instituto Brasileiro de Geografia e Estatística. Censos Demográficos 1950, 1960, 1970,1980, 1991, 2000 e 2010. Disponível em: <www.ibge.gov.br>.

LEFEBVRE, Henry. O direito a cidade. Tradução de Rubens Eduardo Frias. São Paulo: Centauro, 2001.

MARICATO, Erminia. Habitação e cidade. 7 ed. São Paulo:Atual, 1997. 79p.

NASCIMENTO, Plínio Andrade Guimarães do. Dinâmica da produção do espaço urbano e habitação popular na cidade de Ituiutaba (MG): uma análise dos conjuntos habitacionais jardim Europa, Residencial Carlos Dias Leite e Residencial Tupã Ituiutaba (MG). 2011. 103f. Trabalho de conclusão de curso (Graduação em Geografia) - Faculdade de Ciências Integradas do Pontal, Universidade Federal de Uberlândia, Ituiutaba, 2011. 


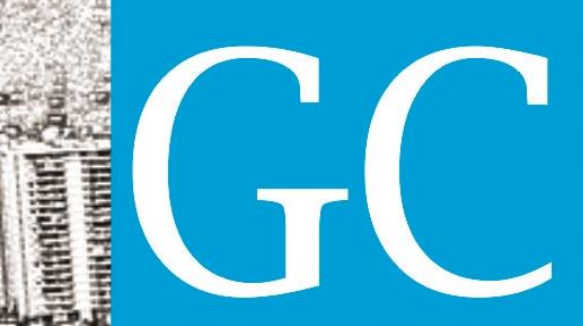

\section{Revista Nacional de}

Gerenciamento de Cidades

OLIVEIRA, Bianca Simoneli de. Ituiutaba (MG) na rede urbana tijucana: (re)configurações sócioespaciais no período de 1950 a 2000. 2003. 204f. Dissertação (Mestrado em Geografia) - Instituto de Geografia, Universidade Federal de Uberlândia, Uberlândia, 2003.

PINHEIRO, Mariana de Vasconcelos. Reprodução do capital e metamorfoses espaciais: um estudo da verticalização de Ponta Negra, Natal/RN. 2011. 188f. Dissertação (Mestrado em Geografia) - Universidade Federal do Rio Grande do Norte, Natal, 2011.

SANTOS, Milton. Metamorfose do espaço habitado. São Paulo: Hucitec, 1996.

SAQUET, Marcos Aurélio. Por uma geografia das territorialidades e das temporalidades: uma concepção multidimensional voltada para a cooperação e para o desenvolvimento territorial. São Paulo: Outras Expressões, 2011.

SOARES, Beatriz Ribeiro et al. Expansão urbana e desigualdades socioespaciais. In: Agentes econômicos e reestruturação urbana e regional: Tandil e Uberlandia. ELIAS, Denise; SPOSITO, Maria Encarnação Beltão; SOARES, Beatriz Ribeiro (orgs.). $1^{\text {a }}$ ed. São Paulo: Expressão Popular, 2010. p. 231-285.

SOUZA, Maria Adélia Aparecida de. A identidade da metrópole: a verticalização em São Paulo. São Paulo: Hucitec, 1994. 163p.

SPOSITO, Eliseu Savério. A vida nas cidades. São Paulo: Contexto, 1994. 90p.

TAVARES, Matheus Augusto Avelino. Os condomínios horizontais fechados e as transformações socioespaciais na cidade de Natal/RN. 2009. 238f. Dissertação (Mestrado em Geografia) Universidade Federal do Rio Grande do Norte, Natal, 2009.

VILLAÇA, Flávio. Espaço intra-urbano no Brasil. 2 ed. São Paulo: Studio Nobel/FAPESP, 2001. 373p. 